\title{
Chiral 1,3,2-Diazaphospholenes as Catalytic Molecular Hydrides for Enantioselective Conjugate Reductions
}

\author{
Solène Miaskiewicz, ${ }^{+}$John H. Reed, ${ }^{+}$Pavel A. Donets, Caio C. Oliveira and Nicolai Cramer*
}

\begin{abstract}
Secondary 1,3,2-diazaphospholenes have a polarized P$\mathrm{H}$ bond and are emerging as molecular hydrides. A class of chiral conformationally restricted methoxy-1,3,2-diazaphospholene catalysts is reported. We demonstrate their catalytic potential in enantioselective 1,4-reduction of $\alpha, \beta$-unsaturated carbonyl derivatives comprising enones, acyl pyrroles and amides in enantioselectivities of up to 95.5:4.5 er.
\end{abstract}

Catalytic asymmetric hydrogenation is an indispensable cornerstone in organic synthesis, with application throughout petrochemical, pharmaceutical, material, and food industries. ${ }^{[1]}$ Transition-metal based catalysts equipped with chiral ligands are the most widely applied, often providing high enantioselectivities and turn-over numbers. ${ }^{[2]}$ The costs and scarcities of precious metals have sparked interest in alternative metal-free methods. ${ }^{[3]}$ Several organocatalytic hydrogenation reactions have emerged, most commonly powered by chiral Brønsted / Lewis acids or bases, ${ }^{[4]}$ as well as frustrated Lewis pairs (FLPs). ${ }^{[5]}$ With the exception of $\mathrm{FLPs},{ }^{[6]}$ the enantiocontrol in metal-free hydrogenations is typically induced by creation of a chiral activating environment of the substrate prior to the reduction event with an achiral hydride donor. ${ }^{[7]}$ The development of chiral organic catalysts able to transfer hydrides to a broad variety of substrates under mild conditions remains an attractive challenge. In this context, Gudat and coworkers discovered the hydridic character of the P-H bond of secondary 1,3,2diazaphospholenes (DAPs) caused by $\sigma$-aromaticity (Scheme 1) ${ }^{[8]}$ Investigations into their reactivity revealed their efficacy in stoichiometric 1,2-reduction of aldehydes and ketones, and selective 1,4-reduction of cinnamaldehyde. ${ }^{[9]}$

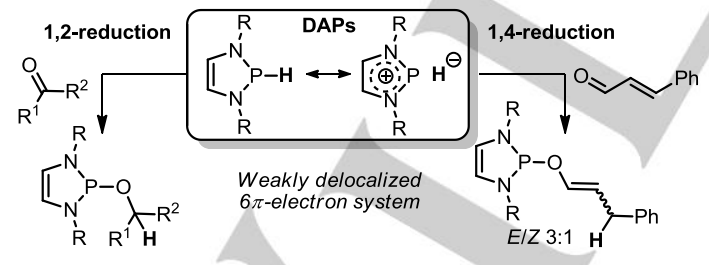

Scheme 1. The hydridic character of DAPs enables reductive transformations

[a] Dr. S. Miaskiewicz, ${ }^{+}$J. H. Reed, ${ }^{+}$Dr. P. A. Donets, Dr. C. C. Oliveira, Prof. Dr. N. Cramer

Laboratory of Asymmetric Catalysis and Synthesis

EPFL SB ISIC LCSA, BCH 4305

1015 Lausanne (Switzerland)

E-mail: nicolai.cramer@epfl.ch

Homepage: http://isic.epfl.ch/lcsa

$\left.{ }^{+}\right] \quad$ These authors contributed equally to this work

Supporting information for this article is given via a link at the end of the document.
Subsequently, transfer hydrogenation of azocompounds with ammonia-borane ${ }^{[10 a]}$ and hydrosilylation of $\mathrm{CO}_{2}{ }^{[10 b]}$ have been disclosed with DAPs. The discovery of facile $\sigma$-bond metathesis between alkoxy-DAP and pinBH by Kinjo was an important advancement, allowing the regeneration of the DAP, thus enabling catalytic reduction of ketones. ${ }^{[1]}$ Moreover, this allowed other groups to consider the use of more stable alkoxy-DAPs as viable precatalysts that are in situ activated by pinBH. Independently, Speed and Kinjo reported 1,4-reductions of $\alpha, \beta$ unsaturated carbonyl derivatives with achiral DAP catalysts in $2017,{ }^{[12 a, b]}$ and more recently hydroboration of pyridines. ${ }^{[12 c, d]}$ Given our longstanding interest in chiral ligand design, ${ }^{[13]}$ we embarked on the development of chiral DAP catalysts capitalizing on diimines that are versatile intermediates in the synthesis of chiral NHCs, ${ }^{[14]}$ diamino phosphine oxides, ${ }^{[15]}$ and phosphordiamidite ligands (Scheme 2). ${ }^{[16]}$ During the preparation of our manuscript, a chiral DAP-catalyzed asymmetric reduction of imines with enantiomeric ratios varying from $55: 45$ to $88: 12$ was reported. ${ }^{[17]}$

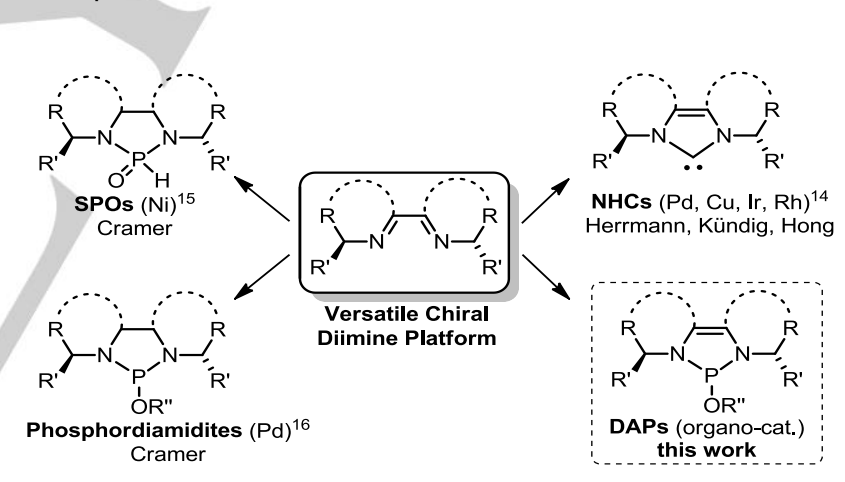

Scheme 2. Expansion of the chiral diimine platform to access DAP catalysts.

The conjugate reduction of acyl pyrrole 1a was selected as initial benchmark transformation (Table 1). The combination of achiral catalyst $\mathbf{P 1}$ and pinBH as terminal reductant provided $88 \%$ of product $2 \mathbf{a}$ at room temperature in acetonitrile (entry 1). Importantly, no reaction occurred when DAP P1 was omitted, excluding any parasitic background reduction (entry 2). A quick survey with DAPs $\mathbf{P 2}$ and $\mathbf{P 3}$ derived from their readily accessible corresponding diimines (see SI), provided encouraging preliminary results (entries 3,4 ). The improved P3 catalyzed the reduction smoothly, giving $2 \mathrm{a}$ in an enantiomeric ratio of $81.5: 18.5$. Despite the initial promising enantiomeric ratios observed with this chiral benzylic-amine-derived catalyst class, it proved difficult to improve the selectivity to synthetically useful levels. We hypothesized that more stringent control of chiral space around the phosphorous atom might be beneficial for the selectivity. In this respect, we identified a constrained cyclic backbone, used in Hong's NHC ligands, ${ }^{[18]}$ as convenient 
way to inhibit bond rotation between the nitrogen and carbon atom bearing the chiral information of the DAP. Rigid DAPs with smaller $\mathrm{R}$ groups, $\mathbf{P 4}(\mathrm{R}=\mathrm{Me})$ and $\mathbf{P 5}(\mathrm{R}=\mathrm{Pr})$, afforded reduction product $\mathbf{2 a}$ in good yields with moderate selectivity (entries 5,6 ). Increasing the bulk of the alkyl substituents (ent-P6, P7 and P8) significantly improved the enantioselectivity to 89:11 er (entries 7-9). Phenyl derivative $\mathbf{P 9}$ provided $\mathbf{2 a}$ in an enantiomeric ratio of 84:16 (entry 10). Notably, aromatic derivatives were simpler to access using our $\mathrm{Cp}^{\mathrm{x}}-\mathrm{Rh}^{\mathrm{III}} \mathrm{C}-\mathrm{H}$ functionalization technology (Scheme 3). ${ }^{[19]}$ The obtained enantio-enriched imidoyl chlorides 3 were dimerized under $\mathrm{Ni}$-catalyzed reductive homocoupling conditions. $^{[20]}$ The envisioned DAPs P9, P10 and P12-17 were accessed by treating 4 with $\mathrm{PBr}_{3}$ and cyclohexene, ${ }^{[21]}$ followed by sodium methoxide.

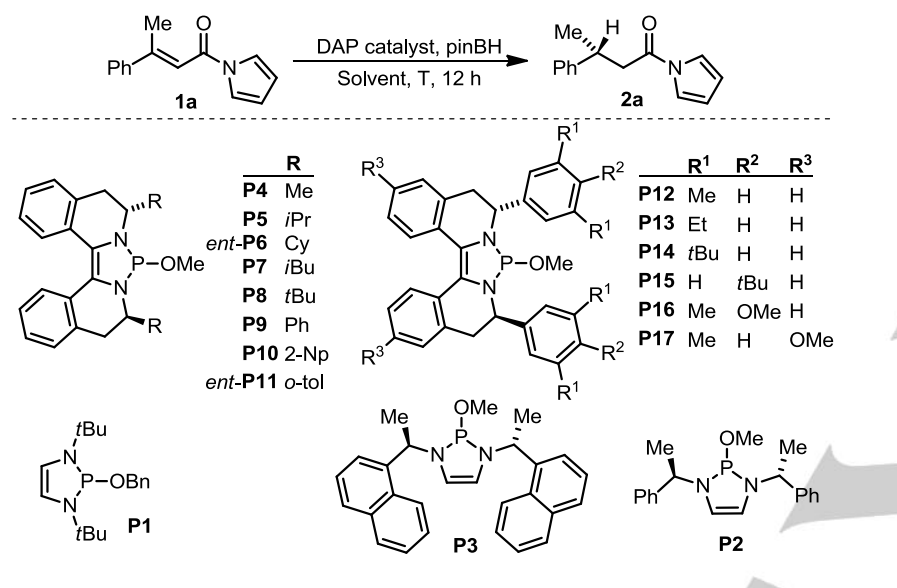

\begin{tabular}{|c|c|c|c|c|c|c|}
\hline Entry & $\mathrm{mol} \%$ & DAP & Solvent & $T\left({ }^{\circ} \mathrm{C}\right)$ & Yield $^{[b]}(\%)$ & $e r^{[c]}$ \\
\hline 1 & 10 & P1 & $\mathrm{MeCN}$ & 23 & 88 & - \\
\hline 2 & 0 & - & $\mathrm{MeCN}$ & 23 & 0 & \\
\hline 3 & 10 & P2 & $\mathrm{MeCN}$ & 23 & 90 & $70.5: 29.5$ \\
\hline 4 & 10 & P3 & $\mathrm{MeCN}$ & 23 & 91 & $81.5: 18.5$ \\
\hline 5 & 10 & P4 & $\mathrm{MeCN}$ & 23 & 75 & $66.5: 33.5$ \\
\hline 6 & 10 & P5 & $\mathrm{MeCN}$ & 23 & 84 & $66: 34$ \\
\hline 7 & 10 & ent-P6 & $\mathrm{MeCN}$ & 23 & 75 & $24: 76$ \\
\hline 8 & 10 & P7 & $\mathrm{MeCN}$ & 23 & 78 & $72: 28$ \\
\hline 9 & 10 & P8 & $\mathrm{MeCN}$ & 23 & 72 & $89: 11$ \\
\hline 10 & 10 & P9 & $\mathrm{MeCN}$ & 23 & 75 & $84: 16$ \\
\hline 11 & 10 & P10 & $\mathrm{MeCN}$ & 23 & 84 & 79.5:20.5 \\
\hline 12 & 10 & ent-P11 & $\mathrm{MeCN}$ & 23 & 75 & $21: 79$ \\
\hline 13 & 10 & P12 & $\mathrm{MeCN}$ & 23 & 88 & $88.5: 11.5$ \\
\hline 14 & 10 & P13 & $\mathrm{MeCN}$ & 23 & 79 & $84.5: 15.5$ \\
\hline 15 & 10 & P14 & $\mathrm{MeCN}$ & 23 & 66 & $84: 16$ \\
\hline 16 & 10 & P15 & $\mathrm{MeCN}$ & 23 & 84 & $84: 16$ \\
\hline 17 & 10 & P16 & $\mathrm{MeCN}$ & 23 & 77 & $86.5: 13.5$ \\
\hline
\end{tabular}

\begin{tabular}{lllllll}
18 & 10 & $\mathbf{P 1 7}$ & MeCN & 23 & 91 & $88.5: 11.5$ \\
19 & 10 & $\mathbf{P 1 7}$ & THF & 23 & 87 & $87: 13$ \\
20 & 10 & $\mathbf{P 1 7}$ & PhMe & 23 & 99 & $91: 9$ \\
21 & 10 & $\mathbf{P 1 7}$ & PhMe & 2 & 95 & $93.5: 6.5$ \\
22 & 5 & $\mathbf{P 1 7}$ & PhMe & 2 & 97 & $93.5: 6.5$ \\
23 & 5 & $\mathbf{P 1 7}$ & PhMe & -10 & 76 & $93.5: 6.5$ \\
24 & 5 & $\mathbf{P 1 7}$ & PhMe & -35 & 9 & \\
\hline
\end{tabular}

[a] $0.1 \mathrm{mmol} 1 \mathrm{a}, 0.15 \mathrm{mmol}$ pinBH, $5-10 \mathrm{~mol} \%$ DAP catalyst, $1.0 \mathrm{M}$ in the indicated solvent and temperature for $12 \mathrm{~h}$. [b] isolated yield. [c] determined by HPLC analysis with a chiral stationary phase.

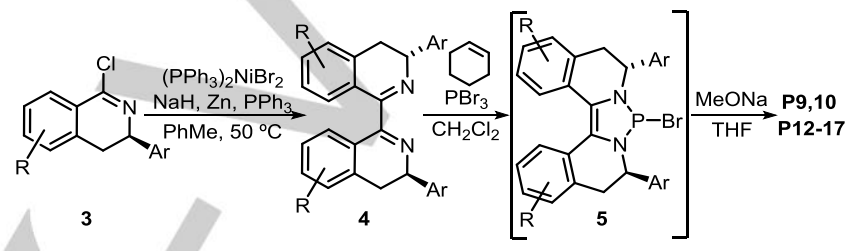

Scheme 3. Synthesis of aryl-substituted DAP catalysts.

In terms of catalytic performance, enhanced bulk proximal to the phosphorous center through replacement of the phenyl group with a 2-naphthyl (entry 11) or ortho-tolyl moiety (entry 12) was not successful. The addition of substituents in the meta-position was beneficial in the case of the 3,5-xylyl group, resulting in the formation of $2 \mathrm{a}$ with $88.5: 11.5$ er (entry 13). However, bulkier 3,5-di-ethyl or 3,5-di-tert-butyl phenyl groups, as well as parasubstituted arenes, were inferior in terms of reactivity and selectivity (entries 14-17). Compound P17 having 3,5-xylyl substituents and a methoxy group on the backbone was retained as the best performing catalyst and most easily purified (entry 18). A brief screen of solvents with P17 identified toluene as superior solvent (entry 20). This permitted running the reaction at $2{ }^{\circ} \mathrm{C}$, improving the selectivity to 93.5:6.5 er (entry 21). Moreover, the catalyst loading could be reduced to $5 \mathrm{~mol} \%$ without any effect on the reaction outcome (entry 22). However, lowering the temperature to $-10{ }^{\circ} \mathrm{C}$ did not improve the ee, and catalyst turnover ceased at $-35^{\circ} \mathrm{C}$ (entries 23,24 ).

With the optimized conditions, the scope of the reaction was explored (Scheme 4). A variety of $\alpha, \beta$-unsaturated acyl pyrroles proved to be suitable substrates, providing access to the reduced products 2a-k. Changing the $R^{2}$ substituent from a methyl group to a longer alkyl chain had little influence on the enantioselectivity or yield. The intrinsic properties of the aryl substituents were evaluated. Both electron-donating and electron-withdrawing groups could be introduced at various positions on the arene, having little effect on reactivity, affording products 2a-k in high yields and enantioselectivities (up to $97 \%$, 93.5:6.5 er). A cyclic substrate reacted well and gave product $\mathbf{2 l}$ in $97 \%$ yield, albeit with a slightly lower enantiomeric ratio. Notably, dialkyl-substituted $\alpha, \beta$-unsaturated acyl pyrroles $\mathbf{1 m}$ and 1n were efficiently reduced. The conjugated double bond of 
isoprene derived substrate $\mathbf{1 m}$ was selectively reduced with moderate enantioselectivity. Substrate $\mathbf{1 n}$, bearing a tert-butyl substituent, gave $\mathbf{2 n}$ in an 89:11 er. In addition to $\alpha, \beta$ unsaturated acyl pyrroles, chalcones 10-t were smoothly reduced to the corresponding ketones 20-t. Again, modulation of the electronic properties of the aryl groups had little impact on the reaction. Furthermore, benzylideneacetone afforded $\mathbf{2 u}$ with 91.5:8.5 er. Notably, more challenging $\alpha, \beta$-unsaturated amides proved to be competent substrates. Primary amide substrate $1 \mathbf{v}$ could be reduced to $2 \mathbf{v}$ with $86: 14$ er at room temperature. Secondary amide $\mathbf{1} \mathbf{w}$ reacted as well, with reduced selectivity.

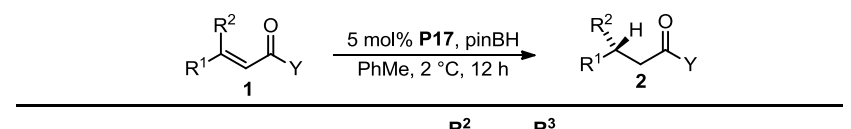

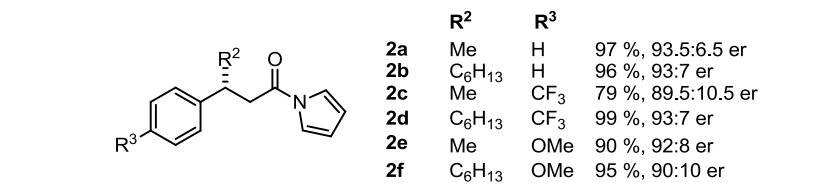<smiles>C[C@@H](CC(=O)n1cccc1)c1ccc2c(c1)OCO2</smiles>

2 g $84 \%, 90.5: 9.5$ er<smiles>C[C@@H](CC(=O)n1cccc1)c1cccc(C(F)(F)F)c1</smiles>

2h $84 \%, 91: 9$ er

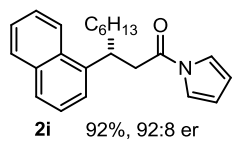<smiles>[R]c1ccccc1[C@H](C)CC(=O)n1cccc1</smiles>

2j $\stackrel{\mathbf{R}^{3}}{\mathrm{~F}} 91 \%, 95.5: 4.5$ er<smiles>O=C(C[C@@H]1CCCc2ccccc21)n1cccc1</smiles>

21 $97 \%, 76: 24$ er<smiles>CC(C)=CCC[C@H](C)CC(=O)n1cccc1</smiles>

2 m $96 \%, 72: 28$ er<smiles>CC(C)(C)CC(=O)n1cccc1</smiles>

2n $88 \%, 89: 11$ er<smiles>[R]c1ccc([C@@H](C)CC(=O)c2ccccc2)cc1</smiles>

2o $\stackrel{\mathbf{R}^{3}}{\mathrm{H}} 95 \%, 92: 8 \mathrm{er}$ 2p $\mathrm{CF}_{3} 96 \%, 86: 14 \mathrm{er}$ $2 q \mathrm{Cl} 96 \%, 85.5: 14.5 \mathrm{er}$

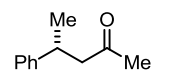

$$
\text { 夏 }{ }_{\mathrm{NH}_{2}}
$$

2u $87 \%, 91.5: 8.5$ er

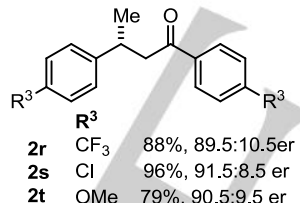

$$
\text { Me } \overbrace{\mathrm{NHPh}}^{\mathrm{O}}
$$

2w $63 \%, 69: 31$ er 2t OMe $79 \%, 91.5: 8.5$ er

[a] $0.1 \mathrm{mmol} 1,0.15 \mathrm{mmol}$ pinBH, $5 \mathrm{~mol} \% \mathrm{P} 17,1.0 \mathrm{M}$ in toluene at $2{ }^{\circ} \mathrm{C}$ for 12 h; [b] at $23^{\circ} \mathrm{C}$ with $10 \mathrm{~mol} \% \mathrm{P} 17$.

Scheme 4. Reduction of $\alpha, \beta$-unsaturated carbonyl derivatives

To gain insights into the origin of enantioselection, single crystals of the standout precatalyst $\mathbf{P} 17$ were submitted to X-ray crystallographic analysis (Figure 1). ${ }^{[2]}$ The profile-view of the structure shows pronounced splaying of the isoquinoline moieties, resulting in an arrangement typical of binaphthyl-type ligands. This aromatic backbone plays the role of a conformational lock, rigidifying catalyst structure. As expected, the diazaphospholene moiety is completely planar, and the methoxy substituent on the phosphorous atom points out of plane. According to seminal reports by Gudat, ${ }^{[8]} \mathrm{P}-\mathrm{H}$ bond orientation in the active catalyst should also be perpendicular to this plane as a result of $\mathrm{sp}^{3}$-hybridization at phosphorous. These features force the bulky aromatic selector units into a pseudo axial orientation. This results in a favored approach to the active $\mathrm{P}-\mathrm{H}$ site via two accessible quadrants, and a pronounced

shielding of the two remaining ones. Taking this into account, we propose the depicted stereoselectivity model, in which the larger substituents on the substrate ( $R_{L}$ and COR) occupy the empty quadrants, leading to the corresponding $(R)$-enantiomers.
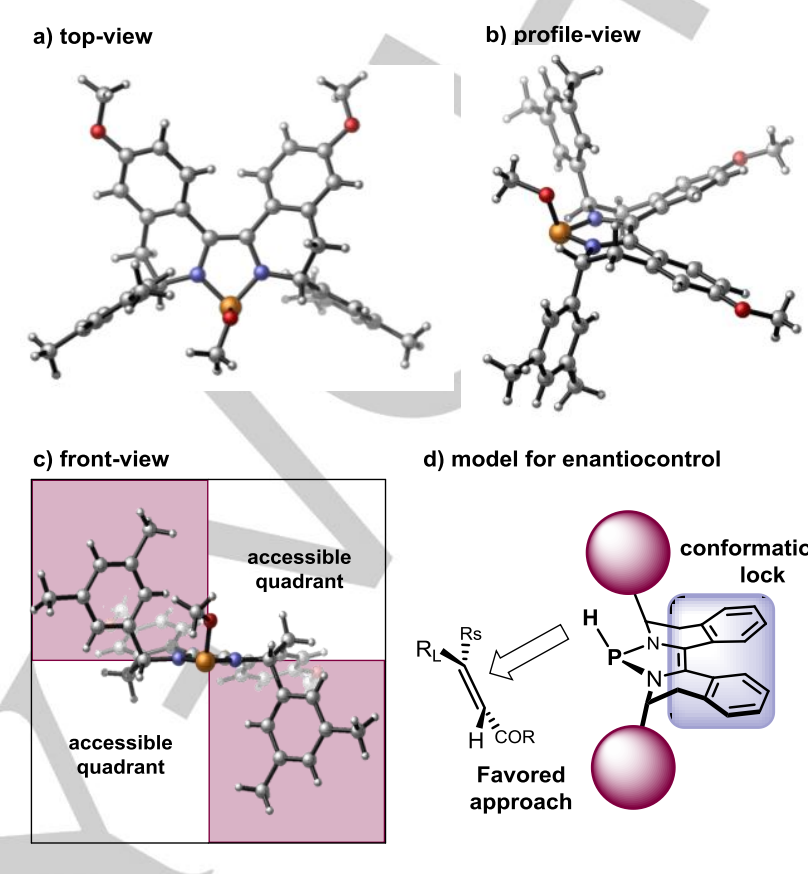

d) model for enantiocontrol

Figure 1. X-ray structure of P17 and a selectivity model for the asymmetric reduction.

Based on NMR observations, the following catalytic cycle for the 1,4 -hydroboration of $\alpha, \beta$-unsaturated carbonyl derivatives is suggested (Scheme 5). The active DAP catalyst $\mathbf{B}$ is rapidly generated via $\sigma$-bond metathesis from precatalyst $\mathbf{A}$ and pinBH. Subsequent addition of $\mathbf{B}$ across olefin substrate $\mathbf{1}$ leads to a mixture of intermediates $\mathbf{C}$ and $\mathbf{C}^{\prime}$. Stoichiometric ${ }^{31} \mathrm{P}-\mathrm{NMR}$ experiments indicate four new species, suggesting that both carbon- (syn, ant $i)$ and oxygen-bound $(E, Z)$ intermediates are formed (see SI). At the current stage, it is unclear whether they are formed directly by 1,4- (6-membered TS) and 3,4-additions (4-membered TS), or - more likely - by interconversion. The catalytic cycle is closed by reaction of the terminal reducing agent, pinBH with these species, giving boron enolate $\mathbf{D}$ and catalyst B (path a). Reduced product $\mathbf{2}$ is obtained after hydrolytic workup. Moreover, NMR-studies with stoichiometric amounts of $\mathbf{A}$ point to an additional scenario (path b). In this case, the formed pinBOMe undergoes $\sigma$-bond metathesis with intermediates $\mathbf{C}$, forming the same final hydroboration product $\mathbf{D}$, simultaneously regenerating precatalyst $\mathbf{A}$. Although this could be a minor pathway in a catalytic reaction due to the higher concentration of pinBH with respect to pinBOMe, it may guide the design of catalytic cycles with enhanced turn-over frequencies. 


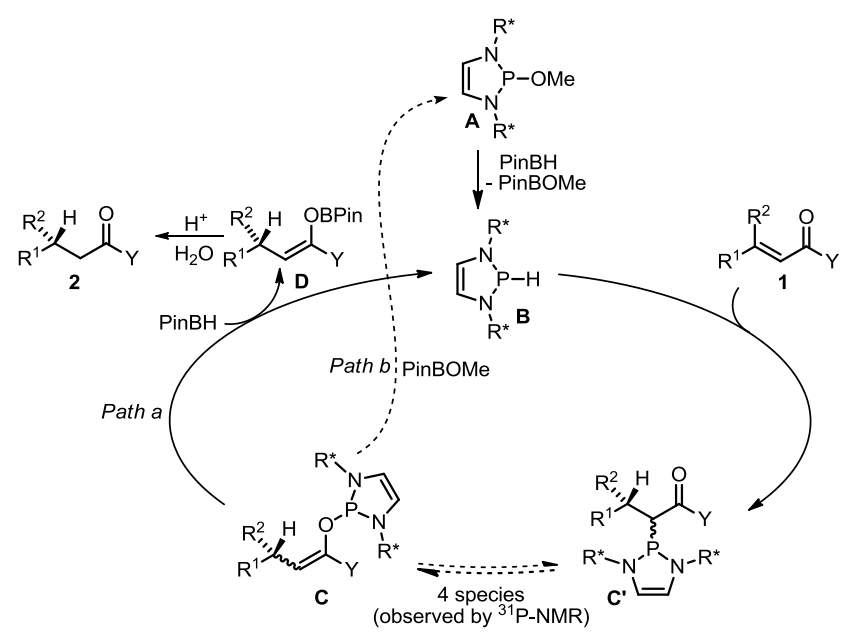

Scheme 5. Mechanism of the DAP-catalyzed reduction

In summary, we report a new class of chiral 1,3,2diazaphospholenes that catalyze enantioselective 1,4-reduction of $\alpha, \beta$-unsaturated carbonyl compounds. These findings underscore the large untapped potential of diazaphospholenes as new axis of phosphorous-based organo-catalysts. Further improvement and applications of these chiral hydride transfer agents in other enantioselective transformations is currently ongoing in our laboratory.

\section{Acknowledgements}

This work is supported by Swiss National Science Foundation ( $N^{\circ} 155967$ and 175507). We thank Dr. R. Scopelliti and Dr. F. Fadaei Tirani for X-ray analysis of P17.

Keywords: 1,3,2-diazaphospholenes • phosphorus • asymmetric catalysis $\bullet$ 1,4-reduction $\cdot$ chiral hydride

[1] a) Handbook of Homogeneous Hydrogenation (Eds.: J. G. de Vries, C. J. Elsevier) Wiley-VCH, Weinheim, 2006; b) D. Wang, D. Astruc, Chem. Rev. 2015, 115, 6621.

[2] Selected reviews: a) T. Okhuma, M. Kitamura, R. Noyori in Catalytic Asymmetric Synthesis (Ed.: I. Ojima), John Wiley \& Sons, Inc., 2000, pp. 1-110; C=C b) S. Kraft, K. Ryan, R. B. Kargbo, J. Am. Chem. Soc. 2017, 139, 11630; c) C. Margarita, P. G. Andersson, J. Am. Chem. Soc 2017, 139, 1346; C=O d) Y.-Y. Li, S.-L. Yu, W.-Y. Shen, J.-X. Gao, Acc. Chem. Res. 2015, 48, 2587; C=N e) W. Li, X. Zhang in Stereoselective Formation of Amines, Topics in Current Chemistry, Springer, Berlin, Heidelberg, 2013, pp. 103-144.
[3] a) K. Revunova, G. I. Nikonov, Dalton Trans. 2015, 44, 840; b) S. Rossi, M. Benaglia, E. Massolo, L. Raimondi. Catal. Sci. Technol. 2014, 4 2708.

[4] a) Comprehensive Enantioselective Organocatalysis: Catalysts, Reactions, and Applications (Ed: P. I. Dalko), Wiley-VCH Verlag GmbH \& Co. KGaA: Weinheim, Germany, 2013; b) M. Rueping, J. Dufour, F. R. Schoepke, Green Chem. 2011, 13, 1084

[5] a) D. J. Scott, M. J. Fuchter, A. E. Ashley, Chem. Soc. Rev. 2017, 46, 5689; b) L. J. Hounjet, D. W. Stephan, Org. Process Res. Dev. 2014 18,$385 ;$ c) J. Paradies in SpringerLink; Topics in Organometallic Chemistry, Springer, Berlin, Heidelberg, 2017, pp. 1-24.

[6] a) L. Shi, Y.-G. Zhou, ChemCatChem 2015, 7, 54; b) W. Meng, X. Feng, H. Du, Acc. Chem. Res. 2018, 51, 191.

[7] C. Zheng, S.-L. You, Chem. Soc. Rev. 2012, 41, 2498.

[8] (a) D. Gudat, A. Haghverdi, M. Nieger, Angew. Chem., Int. Ed. 2000, 39, 3084; Angew. Chem. 2000, 112, 3211; For a review, see: b) D. Gudat, Dalton Trans. 2016, 45, 5896.

[9] a) S. Burck, D. Gudat, M. Nieger, W.-W. Du Mont, J. Am. Chem. Soc. 2006, 128, 3946; (b) D. Gudat, Acc. Chem. Res. 2010, 43, 1307.

[10] a) C. C. Chong, H. Hirao, R. Kinjo, Angew. Chem., Int. Ed. 2014, 53 , 3342; Angew. Chem. 2014, 126, 3410; b) C. C. Chong, R. Kinjo, Angew. Chem., Int. Ed. 2015, 54, 12116; Angew. Chem. 2015, 127, 12284.

[11] C. C. Chong, H. Hirao, R. Kinjo, Angew. Chem., Int. Ed. 2015, 54, 190; Angew. Chem. 2015, 127, 192

[12] a) M. R. Adams, C.-H. Tien, B. S. N. Huchenski, M. J. Ferguson, A. W. H. Speed, Angew. Chem., Int. Ed. 2017, 56, 6268; Angew. Chem. 2017, 129, 6364; b) C. C. Chong, B. Rao, R. Kinjo, ACS Catal. 2017, 7, 5814. c) B. Rao, C. C. Chong, R. Kinjo, JACS 2018, 140, 652.

[13] a) M. D. Wodrich, B. Ye, J. F. Gonthier, C. Corminboeuf, N. Cramer Chem. Eur. J. 2014, 20, 15409; b) P. A. Donets, N. Cramer, Angew. Chem. Int. Ed. 2015, 54, 633; Angew. Chem. 2015, 127, 643; c) J. Pedroni, N. Cramer, Chem. Commun. 2015, 51, 17647; d) B. Ye, N. Cramer, Acc. Chem. Res. 2015, 48, 1308; e) C. G. Newton, D. Kossler N. Cramer, J. Am. Chem. Soc. 2016, 138, 3935.

[14] a) D. Janssen-Müller, C. Schlepphorst, F. Glorius, Chem. Soc. Rev. 2017, 46, 4845; b) D. Zhao, L. Candish, D. Paul, F. Glorius, ACS Catal 2016, 6, 5978; Ir, Rh: c) D. Baskakov, W. A. Herrmann, E. Herdtweck S. D. Hoffmann, Organometallics 2007, 26, 626; Pd: d) E. P. Kündig, T. M. Seidel, Y. Jia, G. Bernardinelli, Angew. Chem., Int. Ed. 2007, 46, 8484; Angew. Chem. 2007, 119, 8636; Cu e) D. Hirsch-Weil, K. A. Abboud, S. Hong, Chem. Commun. 2010, 46, 7525.

[15] P. A. Donets, N. Cramer, J. Am. Chem. Soc. 2013, 135, 11772

[16] J. Pedroni, N. Cramer, J. Am. Chem. Soc. 2017, 139, 12398.

[17] M. R. Adams, C.-H. Tien, R. McDonald, A. W. H. Speed, Angew. Chem., Int. Ed. 2017, 56, 16660; Angew. Chem. 2017, 129, 16887.

[18] M. J. Rodig, H. Seo, D. Hirsch-Weil, K. A. Abboud, S. Hong, Tetrahedron Asymmetry 2011, 22, 1097.

[19] B. Ye, N. Cramer, Science 2012, 338, 504.

[20] G. Lin, R. Hong, J. Org. Chem. 2001, 66, 2877.

[21] J. W. Dube, G. J. Farrar, E. L. Norton, K. L. S. Szekely, B. F. T. Cooper C. L. B. Macdonald, Organometallics 2009, 28, 4377.

[22] Crystallographic data for P17: CCDC 1819312 contains the supplementary crystallographic data for this paper. These data can be obtained free of charge from The Cambridge Crystallographic Data Centre via www.ccdc.cam.ac.uk/data request/cif. 


\section{COMMUNICATION}

A class of chiral 1,3,2diazaphospholenes with rigidified backbones has been developed. As first benchmark transformation, they are shown to behave as catalytic molecular hydrides for enantioselective 1,4-reductions.

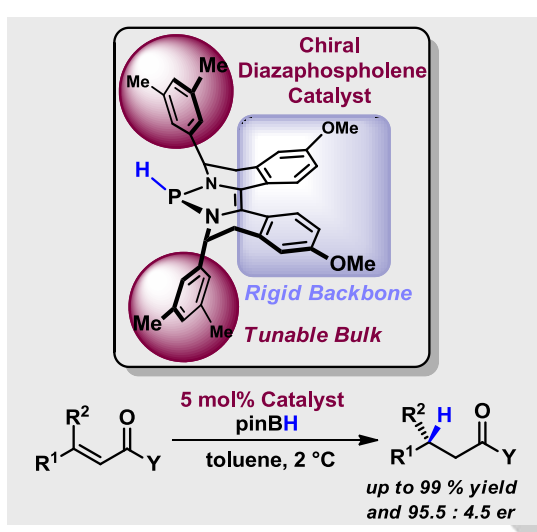

Solène Miaskiewicz, ${ }^{+}$John H. Reed, Pavel A. Donets, Caio C. Oliveira and Nicolai Cramer

Page No. - Page No.

Chiral 1,3,2-Diazaphospholenes as Catalytic Molecular Hydrides for Enantioselective Conjugate 